Received: 2018.03.04 Accepted: 2018.07.30 Published: 2018.10.19

\section{Chronic Thromboembolic Pulmonary Hypertension and Antiphospholipid Syndrome with Immune Thrombocytopenia: A Case Report}

Authors' Contribution: Study Design A Data Collection B Statistical Analysis C Data Interpretation D Manuscript Preparation E Literature Search F Funds Collection $G$
ABEF 1,2 Andris Skride

E 1 Matiss Sablinskis

F 1,2 Kristaps Sablinskis

E 1,3 Sandra Lejniece

E 1,4 Aivars Lejnieks

D 5 Walter Klepetko

BDEF 6 Irene M. Lang
2 Department of Cardiology, Pauls Stradins Clinical University Hospital, Riga, Latvia

3 Department of Hematology, Riga East University Hospital, Riga, Latvia

4 Department of Endocrinology, Riga East University Hospital, Riga, Latvia

5 Department of Thoracic Surgery, Vienna General Hospital, Vienna, Austria

6 Department of Internal Diseases, Vienna General Hospital, Vienna, Austria
1 Riga Stradins University, Riga, Latvia
Corresponding Author: Conflict of interest:

\begin{tabular}{|c|c|}
\hline Patient: & Male, 23 \\
\hline Final Diagnosis: & Antiphospholipid syndrome \\
\hline Symptoms: & Dyspnea \\
\hline Medication: & - \\
\hline Clinical Procedure: & Right heart catheterization \\
\hline Specialty: & General and Internal Medicine \\
\hline Objective: & Rare disease \\
\hline Background: & $\begin{array}{l}\text { Antiphospholipid syndrome is an autoimmune disorder characterized by a hypercoagulable state associated } \\
\text { with circulating antiphospholipid antibodies. The presence of antiphospholipid antibodies can result in a variety } \\
\text { of clinical symptoms, such as thrombocytopenia, stillbirth, endocardial pathologies, and recurrent pulmonary } \\
\text { embolism. }\end{array}$ \\
\hline Case Report: & $\begin{array}{l}\text { We present the case of a } 23 \text {-year-old man with antiphospholipid syndrome and chronic thromboembolic pul- } \\
\text { monary hypertension who developed severe thrombocytopenia. The patient died from right heart failure before } \\
\text { the thrombocytopenia could be managed, preventing performance of a pulmonary endarterectomy procedure. }\end{array}$ \\
\hline Conclusions: & $\begin{array}{l}\text { Managing platelet counts in patients with antiphospholipid syndrome prior to major surgery is very problematic, } \\
\text { and requires similar treatment strategy as in patients with immune thrombocytic thrombocytopenia. Platelet } \\
\text { transfusions may further decrease platelet count, as it can trigger formation of new antibodies. }\end{array}$ \\
\hline
\end{tabular}

MeSH Keywords: $\quad$ Antiphospholipid Syndrome • Hypertension, Pulmonary • Purpura, Thrombocytopenic, Idiopathic

Abbreviations: $\quad$ aPL - antiphospholipid antibodies; APS - antiphospholipid syndrome; CTEPH - chronic thromboembolic pulmonary hypertension; ITP - immune thrombocytopenic purpura; PEA - pulmonary thromboendarterectomy; PAWP - pulmonary artery wedge pressure

Full-text PDF: https://www.amjcaserep.com/abstract/index/idArt/909778 


\section{Background}

Antiphospholipid syndrome (APS) is an autoimmune disorder characterized by a hypercoagulable state associated with circulating antiphospholipid antibodies (aPL) [1]. The presence of aPL can result in variety of clinical symptoms, such as thrombocytopenia, stillbirth, endocardial pathologies, and recurrent pulmonary embolism. Thrombocytopenia can be present in as many as $23.4 \%$ of APS cases [2].

Antiphospholipid antibodies are commonly found in patients with immune thrombocytopenic purpura (ITP), but the clinical significance is still controversial [3].

Mechanisms of thrombocytopenia associated with APS can vary. It can occur due to immune-mediated clearance of platelets, as seen in ITP patients, or less frequently as a consequence of interaction between aPL and platelets triggering aggregation and thrombosis [4].

Due to similar pathogenetic mechanisms, patients with both aPL and thrombocytopenia are treated as ITP. The preferred first-line treatment is oral prednisone $1-2 \mathrm{mg} / \mathrm{kg} /$ day, but it is possible to use higher and lower doses of prednisone or methylprednisolone. Patients who are unresponsive or intolerant to glucocorticoids can be treated with immunosuppressive drugs such as azathioprine and cyclophosphamide. Intravenous immunoglobulin is used in patients with lifethreatening bleeding or to rapidly increase platelet counts. Rituximab, which has been used off-label in ITP patients, has also proven itself to be effective in APS-associated thrombocytopenia [5]. Splenectomy should be postponed for as long as possible, and done only for patients who are unresponsive to glucocorticoids and immunosuppressants.

Antiphospholipid syndrome may result in various clinical syndromes, and CTEPH is one of them [6]. Chronic thromboembolic pulmonary hypertension is classified as group 4 pulmonary hypertension caused by chronic thromboembolic obstruction and clinically manifests as exercise intolerance, fatigue, and progressive dyspnea on exertion [7]. Chronic thromboembolic pulmonary hypertension stands out from other types of pulmonary hypertension because it is curable by pulmonary endarterectomy (PEA) [8]. Pulmonary endarterectomy requires a median sternotomy, cardiopulmonary bypass, and periods of deep hypothermic circulatory arrest. Twenty-minute periods of hypothermic circulatory arrest ensures a bloodless surgical field. It is done in expert centers only, as the procedure is very complex. Studies have shown that quality of life and life expectancy increase for a majority of patients after PEA $[9,10]$.
Table 1. Antiphospholipid syndrome antibodies.

\begin{tabular}{|c|c|c|}
\hline \multirow[b]{2}{*}{ Parameter } & \multicolumn{2}{|c|}{ Date } \\
\hline & First visit & $\begin{array}{c}12 \text { weeks } \\
\text { after }\end{array}$ \\
\hline $\begin{array}{l}\text { IgG phospholipid antibodies, } \\
\mathrm{U} / \mathrm{ml}(\mathrm{RI}<15 \mathrm{U} / \mathrm{ml})\end{array}$ & 63 & 67 \\
\hline $\begin{array}{l}\text { IgM phospholipid antibodies, } \\
\mathrm{U} / \mathrm{ml}(\mathrm{RI}<15 \mathrm{U} / \mathrm{ml})\end{array}$ & 3.5 & 5.1 \\
\hline $\begin{array}{l}\text { lgG, Anti- } \beta 2 \mathrm{GPI} \text { antibodies, } \\
\mathrm{U} / \mathrm{ml}(\mathrm{RI}<15 \mathrm{U} / \mathrm{ml})\end{array}$ & 84 & 73 \\
\hline
\end{tabular}

\section{Case Report}

A 23-year-old man was referred to Pauls Stradins Clinical University Hospital in January 2015 with complaints of progressive dyspnea on exertion (New York Heart Association functional class III). He had been diagnosed with APS in October 2007 (Table 1) when he was hospitalized due to a pulmonary embolism, and was on therapy with vitamin $\mathrm{K}$ antagonist and regular INR monitoring since. The patient had had another pulmonary embolism in 2012. In concomitant therapy, the patient received bisoprolol $10 \mathrm{mg}$ PO daily, torsemide $10 \mathrm{mg}$ PO daily, and spironolactone $50 \mathrm{mg}$ PO daily.

Laboratory results revealed thrombocytopenia with a platelet count of $89 \times 10^{9} / \mathrm{L}$ and INR of 2.0. The patient's liver enzymes were slightly elevated - ALT was $68 \mathrm{U} / \mathrm{L}$ and AST $46 \mathrm{U} / \mathrm{L}$. There were no signs of impaired kidney function. Echocardiography revealed significant right heart dilatation and overload with tricuspid valve regurgitation (grade II-III), mild pericardial effusion, and severe pulmonary hypertension (right ventricular systolic pressure of $70 \mathrm{mmHg}$ ) with a left ventricular ejection fraction of $45 \%$. Estimated central venous pressure (CVP) was $19 \mathrm{mmHg}$.

Computed tomography angiography of the chest showed chronic bilateral thromboemboli of pulmonary artery branches, and fresh thromboemboli of the right pulmonary artery, including total occlusion of the right upper-lobe artery.

On January $5^{\text {th }}, 2015$, the patient underwent right heart catheterization, which confirmed the diagnosis of CTEPH (Table 2).

The patient was started on ambrisentan $5 \mathrm{mg} P O$ on January $6^{\text {th }}$, 2015. Ambrisentan was chosen instead of riociguat because it is state-compensated in Latvia. A team of pulmonary hypertension specialists from PSCUH and Vienna General Hospital decided that the patient should undergo evaluation regarding eligibility for PEA. Therefore, the patient was admitted to Vienna General Hospital on May 2015. On admission, pitting peripheral edema and hepatomegaly were noted. The patient was cyanotic and 
Table 2. Right-heart catheterization.

\begin{tabular}{|cc}
\hline Parameter & Date \\
& $\mathbf{5 . 0 1 . 2 0 1 5}$ \\
\hline PASP, $\mathrm{mmHg}$ & 88 \\
\hline PADP, $\mathrm{mmHg}$ & 40 \\
\hline $\mathrm{mPAP}, \mathrm{mmHg}$ & 57 \\
\hline $\mathrm{CO}, \mathrm{l} / \mathrm{min}$ & 3.30 \\
\hline $\mathrm{Cl}, \mathrm{l} / \mathrm{min} / \mathrm{m}^{2}$ & 1.93 \\
\hline PVR, Wood units & 10 \\
\hline PAWP, mmHg & 23 \\
\hline
\end{tabular}

$\mathrm{Cl}$ - cardiac index; $\mathrm{CO}$ - cardiac output; mPAP - mean pulmonary artery pressure; PADP - pulmonary arterial diastolic pressure; PASP - pulmonary arterial systolic pressure; PAWP - pulmonary arterial wedge pressure; PVR - pulmonary vascular resistance.

had severe dyspnea. Central venous pressure was estimated at $21 \mathrm{mmHg}$. The patient's platelet count was $43 \times 10^{9} / \mathrm{L}$ and he was given 1 bag of platelets on May $16^{\text {th }}$ and started on enoxaparin $40 \mathrm{mg} \mathrm{SC}$. Anti-nuclear antibodies, anti-nuclear neutrophil antibodies, rheumatoid factor, and anti-double-stranded DNA antibodies were negative. The patient was prescribed $75 \mathrm{mg}$ of prednisone PO daily on May $18^{\text {th }}$. Because the platelet count further deteriorated $\left(24 \times 10^{9} / \mathrm{L}\right)$, heparin-induced thrombocytopenia was suspected, but antibodies against platelet factor 4 were negative. Treatment with eltrombopag $50 \mathrm{mg}$ PO daily was started on May $22^{\text {nd }}, 2015$. Eltrombopag is a smallmolecule agonist of the c-mpl receptor, a physiological target of thrombopoietin, and is used to treat ITP that is unresponsive to corticosteroids, immunoglobulins, or splenectomy [11].

Platelet count on June $3^{\text {rd }}, 2015$ was $2 \times 10^{9} /$ L. Due to the increasing inability to oxygenate, the patient was intubated. The patient died on the following day from severe right-heart failure.

An autopsy was done shortly after death and the pathology report confirmed right ventricular hypertrophy with cor pulmonale. There was complete thrombotic occlusion of the right pulmonary artery and several occlusions in peripheral pulmonary artery segments in the left lung. Bone marrow was normocellular. Liver congestion II and pulmonary congestion with edema were present.

\section{Discussion}

The management of the patient was highly complicated due to numerous comorbidities - CTEPH, APS causing progressive thrombocytopenia, and possible concomitant and previously undiagnosed left-heart disease with congestion in lungs and liver.
In cases like this, it is hard to outline any treatment strategy as the correct or the best one.

The possible dysfunction of the left ventricle is suggested by the decreased ejection fraction, notably increased pulmonary artery wedge pressure (PCWP) of $23 \mathrm{mmHg}$ (pre-capillary pulmonary hypertension is characterized by PCWP of $\leq 15 \mathrm{mmHg}$ ), and the autopsy results [7].

The recommended INR for patients with APS is 2.0-3.0 [12]. However, for patients with CTEPH, it should be in the target range of 2.5-3.5, with preferably higher INR in cases of underlying thrombophilia such as APS [7]. This suggests that the anticoagulation therapy was most likely not adequate from 2007 to 2015 , when the patient received a vitamin $\mathrm{K}$ antagonist.

Pulmonary endarterectomy is the treatment of choice for operable CTEPH [8]. Pre-operative risk stratification is essential, with hemorrhagic risk being one of the top priorities. In our case, the patient's platelet count before the planned surgery was $43 \times 10^{9} / \mathrm{L}$, which is below the recommended threshold for major surgery of $50 \times 10^{9} / L$ [13]. Usually, patients with APS have mild thrombocytopenia $\left(>50 \times 10^{9} / \mathrm{L}\right)$ that does not require any special management [5]. There are reports on splenectomy to manage thrombocytopenia in patients with APS in cases where other treatment fails to control platelet counts [14-16]. In this case, splenectomy would be a questionable choice as the patient had severe heart failure and was in a critical state.

Because thrombocytopenia in APS patients is similar to ITP, the treatment remains the same, with glucocorticoids strongly recommended as first-line treatment $[5,17]$. Patients initially unresponsive to glucocorticoids should be receiving immunosuppressive drugs such as azathioprine or cyclophosphamide [1] or immunomodulating agents and intravenous immunoglobulins $[5,17,18]$.

The use of eltrombopag has proven to be highly effective in patients with ITP. Up to $88.8 \%$ of the patients achieve platelet response [19].

Although antiplatelet antibodies were not determined in this case, the available data showing negative antibodies against platelet factor 4 and normocellular bone marrow and no other relevant findings in autopsy, rule out other possible causes of thrombocytopenia in APS, such as heparin-induced thrombocytopenia, thrombotic microangiopathy, bone marrow necrosis, and hemophagocytic syndrome [5].

It is debatable whether other treatment options, such as immunosuppressants, immunoglobulins, or even splenectomy, would have changed the outcome of this case, but it has high educational value and raises awareness of various issues encountered when treating patients with APS. 


\section{Conclusions}

Antiphospholipid syndrome presenting with severe thrombocytopenia still remains a challenge, which requires an individual approach and planned treatment strategy, preceded by thorough patient work-up. All treatment options at hand need to be weighed and managed by an experienced, multidisciplinary team of pulmonologists, hematologists, and surgeons. Since there are no treatment guidelines for thrombocytopenia in APS, more studies are needed to understand the pathogenesis, clinical associations, and management of this condition.

\section{References:}

1. Porres-Aguilar M, Pena-Ruiz MA, Burgos JD et al: Chronic thromboembolic pulmonary hypertension as an uncommon presentation of primary antiphospholipid syndrome. J Natl Med Assoc, 2008; 100: 734-36

2. Cuadrado MJ, Mujic F, Muñoz E et al: Thrombocytopenia in the antiphospholipid syndrome. Ann Rheum Dis, 1997; 56: 94-196

3. Pierrot-Deseilligny Despujol C, Michel M, Khellaf $M$ et al: Antiphospholipid antibodies in adults with immune thrombocytopenic purpura. Br J Heamatol, 2008; 142: 638-43

4. Lim W: Antiphospholipid antibody syndrome. Hematol Am Soc Hematol Educ Progr, 2009; 2009: 233-39

5. Artim-Esen B, Diz-Küçükkaya R, Inanç M: The significance and management of thrombocytopenia in antiphospholipid syndrome. Curr Rheumatol Rep, 2015; 17: 14

6. Kasthuri R, Roubey R: Pulmonary hypertension and the antiphospholipid syndrome. Adv Pulm Hypertension J, 2008; 8: 40-42

7. Galiè N, Humbert M, Vachiery J-L et al: 2015 ESC/ERS Guidelines for the diagnosis and treatment of pulmonary hypertension. Eur Heart J, 2015; 37: 67-119

8. Jenkins D: Pulmonary endarterectomy: The potentially curative treatment for patients with chronic thromboembolic pulmonary hypertension. Eur Respir Rev, 2015; 24: 263-71

9. Freed DH, Thomson BM, Tsui SS et al: Functional and haemodynamic outcome 1 year after pulmonary thromboendarterectomy. Eur J Cardiothorac Surg, 2008; 34: 525-29

10. Ishida K, Masuda M, Tanabe $\mathrm{N}$ et al: Long-term outcome after pulmonary endarterectomy for chronic thromboembolic pulmonary hypertension. Thorac Cardiovasc Surg, 2012; 144: 321-26

\section{Department and Institution where work was done}

Department of Cardiology, Pauls Stradins Clinical University hospital

\section{Conflict of interest}

None.

11. Bussel JB, Cheng G, Saleh MN et al: Eltrombopag for the treatment of chronic idiopathic thrombocytopenic purpura. N Engl J Med, 2007; 357: 2237-47

12. Kim E, Do T, Peacock K, Takundwa PT: Recommended therapeutic INR range for patients with antiphospholipid syndrome on warfarin anticoagulation: Is moderate-intensity (INR 2.0-3.0) or high-intensity (INR 3.1-4.0) better for reducing risk of recurrent thromboembolic events? Cureus, 2016; 8(9): e765

13. American Society of Anesthesiologists Task Force on Perioperative Blood Management: Practice guidelines for perioperative blood management. Anesthesiology, 2015; 122(2): 241-75

14. Hakim AJ, Machin SJ, Isenberg DA: Autoimmune thrombocytopenia in primary antiphospholipid syndrome and systemic lupus erythematosus: The response to splenectomy. Semin Arthritis Rheum, 1998; 28: 20-25

15. Asherson RA, Cervera R, Piette JC, Shoenfeld Y (eds.), The antiphospholipid syndrome II: Autoimmune Thrombosis. Amsterdam: Elsevier, 2002

16. Galindo M, Khamashta MA, Hughes GR: Splenectomy for refractory throm bocytopenia in the antiphospholipid syndrome. Rheumatology, 1999; 38: 848-53

17. Sharma B, Kapoor S, Malaviya AN: Refractory thrombocytopenia in an tiphospholipid syndrome. J Assoc Physicians India, 2005; 53: 147-49

18. Keswani SN: Antiphospholipid syndrome. J R Soc Med, 2002; 95: 336-42

19. González-López TJ, Alvarez-Román MT, Pascual C et al: Eltrombopag safety and efficacy for primary chronic immunethrombocytopenia in clinical practice. Eur J Haematol, 2016; 97(3): 297-302 